\author{
Е.Г. Лукашанеџ \\ Минский государственный лингвистический университет \\ (Белоруссия, Минск) \\ elukashanets@rambler.ru
}

\title{
НОВОЕ СЛОВО И НОВЫЙ СЛОВАРЬ: ПРОБЛЕМЫ ОПИСАНИЯ СЕМАНТИКИ В ОНЛАЙН-СЛОВАРЯХ СЛЕНГА
}

В докладе на материале русского языка рассматриваются онлайн-словари сленга, которые создаются и пополняются самими носителями сленга и существуют только в виртуальном виде. Выявляется важность их исследования для теории неографии. Уделяется внимание проблемам их макро- и микроструктуры: отбору лексики, разграничению многозначных слов и омонимов, наличию большого числа вариантов, структуре словарной статьи. Выявляются параметры статьи онлайнсловаря, которые подразделяются на два типа: параметры, специфичные для онлайн-словарей (дата добавления лексической единицы, автор статьи, рейтинг как отражение его оценки носителями (количество «за» и «против»), наличие тегов (меток), соотносящих слово со сферами его употребления), и параметры, общие для разных типов словарей (характер заглавного слова, семантика слова, отраженная в его дефиниции, и иллюстрации его употребления). На основе анализа более полутора тысяч словарных статей выявляются основные приемы семантизации слов в онлайн-словарях: филологические толкования, синонимы. Устанавливаются отличия этих приемов от тех, которые используются в словарях, созданных профессиональными лингвистами (повторы заглавной единицы, дублирование синонимов, наличие «включений», энциклопедичность толкования, построение толкований как речений-определений).

Ключевые слова: онлайн-словари, сленг, разговорная лексика, словарная статья, толкование.

«Словарь - это моментальный снимок вечно обновляющегося и находящегося в движении языка». Эти слова Ю. Д. Апресяна, сказанные четверть века тому назад (цит. по: [Дубичинский 2008: 15]), были вполне справедливы для того периода, но в настоящее время, к концу второго десятилетия XXI века, ситуация в корне изменилась: Интернет создает для человека новые возможности. В этом докладе делается попытка показать, как меняет Интернет традиционное представление о словарях. 
Влияние Всемирной сети на лексикографию простирается достаточно широко: в настоящее время многие известные словари русского языка, в том числе словари Даля, Ушакова, Кузнецова, Ефремовой, словарь русских народных говоров, словари синонимов, орфоэпические, орфографические словари, существуют в электронном виде, выложены в Интернет. Однако эти словари изначально были созданы на бумажном носителе, а виртуальное их представление - это лишь одна из форм их существования. Но есть и такие словари, возникновение которых вне Сети было бы принципиально невозможным. Это словари сленга и разговорной лексики, создаваемые и пополняемые самими пользователями Интернета, это ресурсы, представляющие собой результат коллективного труда, своего рода краудсорсинговый проект. Именно такие «свободные» словари [Селегей], которые «вовлекают читателя в механизм интерпретации языковых значений» [Перванов], мы и будем далее называть онлайн-словарями.

Первым словарем такого типа явился знаменитый англоязычный словарь «Urban Dictionary» (https://www.urbandictionary.com/), созданный в 1999 г. и на апрель 2014 г., по данным Википедии, содержавший свыше 7 миллионов определений. Первоначальной идеей, вызвавшей словарь к жизни, была идея восполнения материалов обычных, «бумажных» словарей, дополнение их лексическими единицами из речи молодежи и других социальных групп. Успех проекта подтверждается не только почти двадцатилетним существованием данного словаря и стомиллионными ежемесячными просмотрами сайта, но и созданием по его образу многочисленных онлайн-словарей на немецком, французском, итальянском, на славянских языках. Актуальность анализа таких словарей обусловлена не только важностью учета представленного в них материала для неологии и социолектологии, но и необходимостью выявления особенностей металингвистического поведения в интернет-коммуникации носителей сленга.

В конце 2000-х гг. появилось три больших русскоязычных онлайн-словаря, похожих друг на друга по структуре и подбору лексики: «Словоборг» (http://slovoborg. $\mathrm{su} /$ ), «Teenslang» (http://teenslang.su/) и «Словоново» (http://www.slovonovo.ru/). Нами были проанализированы все три словаря, но в наибольшей степени ориентирован на отражение новых слов именно последний, который и явился материалом для доклада.

На время обследования словаря (февраль 2011 - апрель 2012 г.) словарь «Словоново» насчитывал 12522 лексические единицы (ЛЕ). Несмотря на то, что каждую секунду состав словаря может меняться, наши наблюдения показывают, что изменения незначительны (так, число слов с апреля 2012 по январь 2018 г. изменилось с 12522 до 12589, т. е. на 0,5\% единиц), поэтому ими можно пренебречь. Таким образом, мы располагаем довольно большим по объему материалом.

Поскольку субстандарт в высшей степени обладает подвижностью, текучестью, большой динамичностью, варьируясь также и по территории, это обусловливает трудности отражения новой субстандартной лексики в бумажных источниках. Так, если сравнить лексику «Словоново» с лексикой, отраженной в одном из самых последних бумажных словарей молодежного сленга [Никитина 2007], 
то окажется, что лишь чуть более четверти слов онлайн-словаря зафиксировано в бумажном источнике. Остальные слова (если они не имеют местного либо узкопрофессионального характера) представляют собой, по-видимому, неологизмы молодежного языка. Это делает возможным поставить вопрос об особенностях «Словоново» именно как неографического источника. Попытаемся выявить, как решаются в словаре, составленном непрофессионалами, важнейшие проблемы лексикографии.

Первая проблема - это разграничение многозначности и омонимии. В «Словоново» различные значения одной и той же лексической единицы подаются недифференцированно - как внутри статьи, обычно под номерами, так и путем т. н. дублирования статей (т. е. один и тот же или разные авторы дают определения одной лексической единице). Например, щземиться '1. стесняться, 2. бояться, 3. жадничать', ЮАРиться 'ездить в ЮАР (болеть за команду); отдыхать / работать в Южно-Африканской Республике', барбос (17 мая 2008, core_solo) 'должностное лицо, грубо обращающееся с людьми' - барбос (8 декабря 2009, anonymous) 'сторож, охранник’. Дублетных статей (посвященных одной лексической единице) в словаре большое число: на 12522 ЛЕ приходится 16518 словарных статей, причем число их у одной лексической единицы может достигать 33 (слово ОЛОЛО).

Вторая проблема - это тождество слова, или проблема вариантов. Непрофессионализм составителей словаря ведет к тому, что графические, фонетические, словообразовательные варианты подаются вразнобой, либо в отдельных статьях, либо внутри одной статьи: де́иил 'мало, немного' - дещл 'мало, чуть-чуть, крохи, немного', нэт (или нет) 'сокращение от инет', Дрюлик 'сокращение от имени Андрей. Также варианты Дрюля, Дрюня’.

Третья проблема - структура словарной статьи. Статьи в онлайн-словарях включают не только те параметры, которые обычно имеются в традиционных толковых словарях, но и те, которые могут существовать только в словарях, размещенных в Интернете.

1. Параметры, специфичные для онлайн-словарей.

К ним можно отнести: 1) дату добавления слова (создания статьи), 2) автора статьи, 3) рейтинг лексической единицы и 4) теги (метки).

Датирование дублетных статей позволяет определить некоторые особенности добавления слов (изменение, уточнение значений или сфер употребления). Наиболее интересны случаи, когда такие добавления носят как бы характер комментария или чата, добавляющий слово вступает в своеобразную дискуссию с предыдущим автором: тру (13 июня 2008) 'Выражение одобрения. Правдиво, красиво, реально, жизненно’ - тру (2 сентября 2008) ‘Не обязательно выражение одобрения. Означает стопроцентную приверженность, натуральность, идейность'

Реальный автор словарной статьи скрывается за ником, который также указывается далеко не во всех случаях. Так, в словаре «Словоново» из 16518 статей 8583, т. е. 52\%, были анонимными. Однако даже в случае неанонимного автора мы можем констатировать только принадлежность разных словарных статей одному и тому же автору. 
Более интересным параметром является третий - рейтинг лексической единицы. Он может быть рассмотрен двояко: как абсолютный показатель (если суммировать число всех проголосовавших «за» или «против») и как относительный, если вычислять процент положительных (или, напротив, отрицательных) оценок. Первое число, скорее всего, зависит от времени создания словарной статьи. Что касается второго числа - положительной или отрицательной оценки, то предварительные наблюдения показывают, что, возможно, здесь играют роль как минимум два фактора: отношение к самой лексической единице и отношение к характеру ее дефиниции, данной тем или иным автором. Последнее можно проследить на примере разных дефиниций, содержащихся в достаточно больших дублетных статьях. Например, для слова упячка, отмеченного в 22 дублетных статьях, неприятие пользователей вызвали статьи, содержащие неверную, с точки зрения носителей сленга (и с точки зрения лингвиста), этимологию этого слова: 'звукоподражательное от междометия «опачки!»' (9 за, 137 против), 'происходит от слова «упиться», по аналогии со словом «спячка»' (55 за, 563 против). Напротив, в целом положительную оценку получили статьи со следующими дефинициями: 'процесс разрушения всякой определенности' (1114 за, 136 против), 'сайт www.upyachka.ru. А также вся субкультура, которая оттуда пошла' (832 за, 125 против; это определение наиболее точно отражает семантику слова).

Кроме описанных трех параметров, в словарную статью включается такой показатель, как теги (или метки). В большинстве случаев используются пометы с главным термином «сленг», например, слово фара 'неудовлетворительная оценка на экзамене' помечено как студенческий сленг, а слово фе́рма 'виртуальный суперкомпьютер, собранный из множества машин...' - как компьютерный сленг.

2. Параметры, входящие в статью словарей разных типов - как бумажных, так и электронных. В словарной статье онлайн-словарей из всех традиционно выделяемых параметров последовательно представлены только 1) заголовочное слово, 2) семантика и 3 ) иллюстрации.

Носители сленга приводят заголовочные слова в различном написании, что ведет к значительной графической вариантности этих слов: aфpmap / aфmap 'автор', кропаль / крапаль 'немножко'. Заголовочное слово далеко не всегда дается в начальной форме: канонисты 'фотографы, предпочитающие фотоаппараты фирмы Canon', зачехли 'приказ к человеку замолчать', припльли 'закончить неудачно действие'. Наконец, форма заголовочного слова может не соотноситься с формой главного слова дефиниции: лишак 'перебор, лишнее сказать, сделать'

Иллюстрации употребления сленгизмов представляют обычно типизированные контексты из устной речи или интернет-коммуникации: многабукав 'слишком сложный для понимания текст': - Читал отчет? - Многабукав!

Наиболее интересные результаты для исследования металингвистической деятельности носителей сленга позволяет получить анализ семантизации слов. Именно в объяснении значений слов и выражений проявляются особенности онлайн-словарей как словарей сленга, составленных его носителями. Ниже приводятся краткие выводы из анализа 1610 словарных статей, относимых к жаргону наркоманов. 
Толкования могут содержать т. н. включения - сведения, не относящиеся собственно к лексическому значению (указания на грамматические характеристики слов, их происхождение или деривационные связи, их сленговые синонимы или варианты), что может быть обусловлено отсутствием соответствующих пунктов в образце для добавления слова (например, в онлайн-словаре на сайте http:// teenslang.su изначально даются рубрики «происхождение», «синонимы», «варианты»).

Основной прием семантизации (более двух третей статей) - (филологические) описательные толкования, как состоящие из двух-трех слов (папавер 'опийный мак', сеанс 'однократная инъекция наркотика'), так и имеющие более развернутый характер (промокашка 'определенного вида и размера небольшой кусок бумаги, пропитанный диэтиламидом лизергиновой кислоты (LSD-25)'). Поскольку словари сленга отражают специфическую субкультуру, порой бывает недостаточно даже такого пространного филологического определения. Особенно это характерно для лексических единиц из сленга наркоманов: пипетка 'приспособление для курения курительных трав. Используется обычная медицинская пипетка в пластиковой упаковке и пружина от зажигалки. Предварительно сняв с пипетки резиновую часть ... [далее следует многословное описание использования этого предмета - Е. Л.]'. Иногда применяются т. н. речения-определения: чихпильбирим 'Это как шаурма, только вкусней, может означать любую другую еду, предполагается, что он выглядит как сосиска на веревочке'.

Примерно в шестой части случаев семантизация осуществляется через общелитературные синонимы, обычно один, редко два или три (калики 'таблетки', база 'задница, ягодицы'); есть также и отсылки к другому слову (гидропон 'то же самое, что и гидропоника, только сокращенно'). Некоторая часть семантизаций совмещает в себе два типа: начинается с общелитературного синонима, объясняемого далее с помощью дефиниции (федя 'эфедрин, сильный наркотик из ряда амфетаминов'). При семантизации с помощью синонимов нередко происходит дублирование, когда приводится не один, а несколько почти полных синонимов, включая и сленговые: така-така 'травка, конопля, анаша'.

Непрофессионализм создателей словаря приводит к повторам заглавной единицы (сканк 'сканк (англ. skunk, «скунс») - сорта конопли..., обладающие выраженным специфическим запахом...'), а также к использованию в составе толкования слов типа называет, обозначает, название и т. п. (зараза 'название наркотиков, получаемых в домашних условиях'). Та же причина ведет к употреблению в толковании слов нелитературного языка - просторечных, жаргонных, нецензурных (манага 'конопля, вываренная в молоке, и прет так, что просто ... и варится из беспонтовки...').

Таким образом, металингвистическое поведение носителей русского сленга, нашедшее свое выражение в онлайн-словарях, характеризуется следующими чертами: сосредоточение на более или менее новой сленговой лексике данного языка и в то же время стремление охватить как можно больший объем этой лексики и дать максимально полное и точное объяснение употребления слов, что 
проявляется в дублетности статей; желание выразить личностное отношение к лексическим единицам, отражающееся в рейтинговой оценке сленгизмов; разработка гипертекстовых ссылок (тегов), помогающих отобразить сферу употребления лексических единиц; любительский уровень лексикографирования, выражающийся в сильно развитой вариативности, орфографической небрежности и размытости словарных дефиниций. С одной стороны, эти недостатки онлайн-словарей затрудняют их использование лингвистами, так как ведут к необходимости длительной обработки исходных данных с целью приведения их в надлежащий для анализа вид. С другой стороны, привлекает возможность получения большого по объему и достаточно нового по времени возникновения сленгового материала, практически недостижимого при учете только бумажных словарей.

\title{
Литература
}

Дубичинский В.В. Лексикография русского языка: учеб. пособие. М.: Флинта; Наука, 2008. $432 \mathrm{c}$.

Никитина Т. Г. Молодежный сленг: Толковый словарь. М.: Астрель; АСТ, 2007. $910 \mathrm{c}$.

Перванов Я. А. Заметки по электронной лексикографии [Электронный ресурс] // Bсе для студента. URL: https://www.twirpx.com/file/568991/ (дата обращения: 07.01.2018).

Селегей $B$. Электронные словари и компьютерная лексикография [Электронный pecypc] // Файловый архив для студентов. URL: https://studfiles.net/preview/1771482/ page:28/ (дата обращения: 07.01.2018).

\author{
E. G. Lukashanets \\ Minsk State Linguistic University \\ (Belarus, Minsk) \\ elukashanets@rambler.ru
}

\section{A NEW WORD AND A NEW DICTIONARY: PROBLEMS OF THE SEMANTICS DESCRIPTION IN ONLINE DICTIONARIES OF SLANG}

This paper studies online dictionaries of Russian slang which are created and replenished by slang speakers and exist only in virtual form. The importance of their study for the theory of neography is revealed. Attention is paid to the problems of their macroand microstructure: the selection of vocabulary, differentiation of polysemous words and homonyms, the presence of a large number of options, the structure of the dictionary entry. The parameters of the online dictionary entry are identified, they are divided into two types: parameters specific for online dictionaries (the date of adding a lexical unit, the author of the entry, the rating as a reflection of its evaluation by the users (the number of «pros» and «cons»), presence of tags, correlating the word with spheres of its use), and 
parameters common for different types of dictionaries (the character of the headword, the semantics of the word reflected in its definition, and illustrations of its use). Based on the analysis of more than a thousand dictionary entries, the main methods of word semantization in online dictionaries are revealed: philological interpretations, synonyms. The author determines the differences between these techniques from those used in dictionaries created by professional linguists (duplication of the title units and synonyms, presence of «inclusions», encyclopedic interpretation, construction of interpretations as utterances of the definitions).

Key words: online dictionaries, slang, conversational vocabulary, dictionary entry, definition.

\section{References}

Dubichinskii V.V. Leksikografiya russkogo yazyka: uchebnoe posobie [Lexicography of the Russian language: a textbook]. Moscow, Flinta/Nauka Publ., 2008. 432 p.

Nikitina T. G. Molodezhnyi sleng: Tolkovyi slovar' [Youth slang: An explanatory dictionary]. Moscow, Astrel'/AST Publ., 2007. 910 p.

Pervanov Ya. A. Zametki po elektronnoi leksikografi [Notes on electronic lexicography]. Available at: https://www.twirpx.com/file/568991/ (accessed 07.01.2018).

Selegei V. Elektronnye slovari i komp'yuternaya leksikografiya [Electronic dictionaries and computer lexicography]. Available at: https://studfiles.net/preview/1771482/ page:28/ (accessed 07.01.2018). 